Año 9, Núm. 23 (Julio- diciembre 2016)

http://revistainvestigacionacademicasinfrontera.com

ISSN: 2007-8870

Recibido el 12 de agosto de 2016. Dictamen favorable el 286 de octubre de 2016

\title{
La agricultura comercial en el Valle del Mayo, Sonora (1920 -1940)
}

Ernesto Clark Valenzuela

Resumén

Una de las temáticas que no se había abordado suficientemente dentro de la historia económica empresarial son los estudios sobre las empresas y empresarios agrícolas. Hasta que, algunas instituciones e investigadores en el norte y noroeste de México mostraron interés en los últimos años por los estudios de historia empresarial de la agricultura. Teniendo como antecedente la obra del Dr. Mario Cerutti Pignat, investigador de la Universidad Autónoma de Nuevo León, en el noroeste también ha surgido la inquietud por estos estudios a través de un buen número de tesis, libros y artículos sobre historia empresarial agrícola. La Facultad de Historia de la Universidad Autónoma de Sinaloa, el Departamento de Historia y Antropología de la Universidad de Sonora y la Universidad Autónoma de Baja California son instituciones donde se ha generado investigación sobre historia empresarial. Desde fines del siglo XIX y principios del XX, por ejemplo, el sur de Sonora se ha caracterizado por el surgimiento y desarrollo de la actividad agrícola, misma que ha atravesado por diversos momentos. Tras el decaimiento de la minería en Álamos, esos capitales se trasladan paulatinamente al valle del Mayo, donde los ranchos y haciendas sufrieron una transformación al convertirse en empresas agrícolas modernas. Cultivos de exportación como el garbanzo y el trigo fueron determinantes en el desarrollo y construcción del espacio productivo regional permitiendo el surgimiento de áreas urbanas en los municipios de Navojoa, Etchojoa y Huatabampo. En este artículo se analizan las condiciones que originaron la conformación de un empresariado agrícola en el Mayo. Tales como la irrigación, el transporte, la infraestructura financiera. Otro factor importante fue la participación del general Álvaro Obregón Salido como impulsor de la actividad económica en la región al organizar a los productores agrícolas y construir el ferrocarril de Navojoa a Yavaros.

En este trabajo se utilizaron fuentes primarias de archivo, como el Archivo Histórico General del Estado de Sonora (AHGES), el Archivo de Notarías del Estado de Sonora, además de referencias bibliográficas.

Palabras Clave: Historia empresarial, empresarios agrícolas, agricultura comercial, espacio productivo 
Año 9, Núm. 23 (Julio- diciembre 2016)

\section{http://revistainvestigacionacademicasinfrontera.com}

ISSN: $2007-8870$

\section{Introducción}

La reciente historiografía sobre empresas y empresarios en México se ha caracterizado por su heterogeneidad al abordar distintos periodos, regiones y problemáticas. En esta tarea se han presentado dificultades y vacíos temáticos o sectoriales, uno de ellos ha sido la aplicación de estos estudios a la agricultura comercial y de exportación. Se advierte también una relativa ausencia de trabajos sobre la etapa pos-revolucionaria. Este fenómeno, según María del Carmen Collado, puede ser resultado de la dificultad para acceder a archivos de empresas y empresarios más contemporáneos, de las limitaciones impuestas por las notarías para la consulta de sus acervos. Pero sin duda, dice la autora, el celo con el que la élite económica ha resguardado sus actividades de la mirada pública. (Collado, 2000: 53).

En el noroeste, y particularmente en el sur de Sonora, desde fines del siglo XIX surgieron y se desarrollaron espacios productivos ligados a la actividad agrícola de exportación, como fue el Mayo sonorense. Caso que se aborda en este trabajo con el propósito de contribuir al análisis de las condiciones o factores que propiciaron el surgimiento de la agricultura comercial en esa región.

Al igual que en otras regiones, en el Mayo las haciendas y ranchos experimentaron a finales del siglo XIX una tendencia hacia la modernización capitalista de sus principales estructuras productivas y comerciales en respuesta a los cambios que se estaban operando a escala regional y nacional. Se habla de modernización de la agricultura en Sonora, según el invetigador Juan José Gracida Romo, a partir de la década de 1890 cuando ocurre un cambio cualitativo en esta actividad pues aparecen nuevos cultivos y hay innovaciones en los métodos de producción y en las características de las unidades productivas (Gracida, 1985: 96).

La región del Río Mayo, Sonora, geográficamente pertenece al noroeste de México, desciende desde la parte baja de la Sierra Madre Occidental hasta la planicie costera. Histórica y culturalmente forma parte del Mayo, que en su conjunto se ubica entre las cuencas hidrológicas de los ríos Fuerte, en Sinaloa y Mayo en el sur de Sonora, antiguo asentamiento de la etnia del mismo nombre. Gastronómicamente se ubica en los límites de la región del maíz. Climática y 


\section{http://revistainvestigacionacademicasinfrontera.com}

arquitectónicamente se asemeja más a El Fuerte, Sinaloa de Leyva y Los Mochis que a Ciudad Obregón o Guaymas. Con la llegada del ferrocarril en 1907 se integra más a Sonora y su frontera con Estados Unidos. La construcción del ramal de Navojoa al puerto de Yavaros vino a unir y amalgamar los pueblos y comunidades de la cuenca baja del río. Se ha construido su identidad a través del sincretismo religioso, la herbolaria, la música, las danzas del venado (diferente al Yaqui), el pascola y los matachines, la comida, las costumbres ligadas a los ciclos de la naturaleza y su mirada al mar por los diferentes puertos que ha tenido a pesar de las condiciones adversas. ${ }^{1}$

En la construcción de la región, se tiene el antecedente del surgimiento de Álamos, como un centro de gestión regional en el noroeste, a donde arribaron inmigrantes principalmente españoles desde los tiempos de la Colonia, que se dedicaron a la minería y al comercio, constituyendo redes familiares de donde posteriormente emerge una burguesía regional, ingresando algunos a la élite gobernante. Tras la crisis minera en los inicios del siglo XX en la sierra, ocurre una reorganización del espacio regional con el traslado del capital alamense para ser invertido en la agricultura en el valle (Clark, 2006). En este proceso, contribuye de manera importante la colonización, que se aceleró en la década de los años de 1880, cuando surgen más agricultores después de la derrota de las huestes yaquis y mayos de Cajeme en 1886 (Gracida, 2009:31).

El Valle del Mayo tuvo un desarrollo agrícola anterior al del Yaqui caracterizado por el dominio del capital local sobre su colonización, a diferencia de las otras regiones de Sonora donde el capital extranjero y las compañías deslindadoras dominaron la escena (Gracida, 2014:120).

Con la ampliación de los canales de riego y la introducción de nuevos cultivos, entre otras innovaciones, algunas haciendas empezaron a convertirse en empresas que destinaban su producción hacia el consumo externo, regional y local, constituyendo el antecedente de la empresa agrícola capitalista.

${ }^{1}$ Entrevista con el Dr. Juan José Gracida Romo, Hermosillo, Sonora, 20 de junio de 2012. 


\section{http://revistainvestigacionacademicasinfrontera.com}

ISSN: 2007-8870

De acuerdo con el cronista porfiriano Pedro N. Ulloa, durante la primera década del siglo XX, el distrito de Álamos se dividía en trece municipalidades que eran: La Aduana, Álamos, Camoa, Navojoa, Minas Nuevas, Movas, Nuri, Rosario, Promontorios, Quiriego, Río Chico, Etchojoa y Huatabampo, donde se habían formado alrededor de veinte haciendas, cerca de doscientos ranchos y las primeras compañías agrícolas. Algunos de estos propietarios fueron los primeros exportadores de garbanzo (Ulloa, 1910:129-139).

La irrigación.

El recurso agua fue uno de los factores determinantes para abrir al cultivo grandes extensiones de tierra en el sur de Sonora. Los pioneros del uso del agua para fines agrícolas en la región fueron los hermanos Martín, José de Jesús y Juan Salido, quiénes en 1865 abrieron un canal de doce kilómetros de longitud para irrigar las tierras de la hacienda Tres Hermanos. Además de regar tierras de cultivo, el agua del canal se aprovechaba mediante una sencilla cascada como fuerza motriz del primer molino harinero conocido en los contornos (Aguilar Camín, 1986:35-36).

Sin embargo, no fue sino hasta los años de 1890 cuando la irrigación tuvo un impulso importante: entre 1892 y 1902 se habían construido o estaban por construirse sobre la margen derecha del río, nueve canales con una capacidad de conducción total de 35 mil litros; y sobre la izquierda, otros nueve con capacidad de conducción de casi 40 mil litros. (Mange, 1933:42).

En el crecimiento de las obras de irrigación influyeron varios eventos de orden interno y externo, como la pacificación de los indígenas mayos y los trabajos de la Comisión Geográfica Exploradora a fines de la década de 1880, las políticas porfiristas en favor de la agricultura a partir de 1892 (específicamente el permiso a los particulares para construir canales), la colonización del sudoeste norteamericano y la creciente demanda de alimentos que trajo consigo, la introducción de maquinaria y tecnificación de las actividades (fertilizantes, desgranadoras, trilladoras y demás instrumentos), así como la llegada del ferrocarril en 1907, favorecieron ampliamente la explotación de las tierras en escala comercial.

El fomento de la irrigación seguía los patrones porfiristas de concesiones a particulares, fortaleciendo el sector agroexportador de la economía. La legislación del uso del agua se remonta 


\section{http://revistainvestigacionacademicasinfrontera.com}

al año de 1843, cuando se promulgó el Reglamento de Aguas, mismo que fue reformado en 1880, y estuvo en vigor hasta su siguiente modificación en 1905. Se concedía el beneficio de las aguas a los pobladores más antiguos según sus títulos de propiedad, debiendo estar sus terrenos dentro de los fundos legales respectivos (Clark y Carrillo, 2006:30).

Los ayuntamientos, escudados en esa ley, daban preferencia a personas influyentes en las comunidades. Para su funcionamiento, el Gobierno del Estado empezó a celebrar contratos y convenios con particulares para la perforación de pozos artesianos que permitieron obtener agua del subsuelo, también se recurrió a los contratos para la construcción de canales.

La superficie irrigada estaba concentrada en pocas manos, negociaciones como la Compañía Agrícola del Río Mayo, S.A., la compañía Morales y García Peña, la Sociedad Salido Hermanos, la Sociedad José T. Otero e Hijos, la negociación de Orrantia y Quiróz, entre otras, sostenían el control de la infraestructura agrícola y del agua. (Montaño y Gaxiola, 1933:52).

En 1920 se otorgó a la Compañía de Aquichopo, el derecho de aprovechar para riego 3,882 litros por segundo de las aguas broncas del río Mayo para beneficio de 4,642 hectáreas colindantes con las haciendas El Naranjo y los ejidos de los pueblos de Huatabampo y Moroncárit (Radding y Ruiz, 1985:325). 
Año 9, Núm. 23 (Julio- diciembre 2016)

Revista de Investigación

Académica sin Frontera

ISSN: 2007-8870

\section{http://revistainvestigacionacademicasinfrontera.com}

Cuadro 1. Canales de derivación en el Valle del Mayo, 1918.

\begin{tabular}{|c|c|c|}
\hline Nombre del canal & Municipio & Propietario \\
\hline Tres Hermanos & Navojoa & David Roy \\
\hline Santa Bárbara & “ & Alfonso Goycolea \\
\hline Los Pobres de Tesia & “ & Campoy Hermanos ${ }^{1}$ \\
\hline Rosales & “ & $\begin{array}{l}\text { José María y Epifanio Salido, hijos y } \\
\text { sucesores }\end{array}$ \\
\hline Orrantia & “ & Francisco Orrantia \\
\hline Santa Rosa & “6 & Federico Dow \\
\hline San Ignacio & “ & Morales y García Peña \\
\hline Amparán & Etchojoa & Inocente Amparán \\
\hline Bacobampo & “ & José María y Epifanio Salido \\
\hline Zaragoza & Huatabampo & Ponciano I. Castro \\
\hline Chucari & “6 & Cía. Agrícola del Río Mayo \\
\hline La Paz & “6 & Manuel y Francisco Terminel \\
\hline La Villa & “ & Cía. Agrícola La Villa \\
\hline Auxiliar & “6 & Sebastián Chacón \\
\hline Tiriscohuasa & “ & Cía. De Irrigación de Tiriscohuasa \\
\hline Independencia & “ & Cía. De Regadío de Etchojoa \\
\hline Jupagogoli & $\begin{array}{l}\text { Huatabampo y } \\
\text { Etchojoa }\end{array}$ & Cía. del Canal de Jupagogoli \\
\hline General Otero & Huatabampo & Guadalupe viuda de Otero e hijo \\
\hline Huichaca & “ & Ramón e Ildefonso Ross \\
\hline Constitucionalista & “ & Rodolfo Ruiz \\
\hline Naranjo & “ & Sucesores de Jesús Velderráin \\
\hline Libertad & “6 & Cía. De Regadío de Aquichopo \\
\hline
\end{tabular}

Fuente: "Informe relativo a los canales de riego presentado por el ingeniero inspector Gustavo González el 30 de septiembre de 1918”, Archivo Histórico del Agua, Ramo: Aprovechamientos Superficiales, Caja 2146, exp. 32200, ff. 4-15. Citado por Gustavo Lorenzana. 


\section{http://revistainvestigacionacademicasinfrontera.com}

ISSN: 2007-8870

Durante los gobiernos de Obregón y Calles se dio un gran impulso a las obras de riego, de manera que para 1926 la superficie irrigada en el Mayo era de 30,000 hectáreas, distribuidas por municipio de la siguiente manera: Navojoa: 7,500 has; Etchojoa: 13,500 has, y Huatabampo: 9,000 has. En el ciclo 1929 - 1930 las tierras irrigadas representaban la mayoría de las zonas temporaleras que cubrían el 45\% de la superficie total. (Radding y Ruiz, 1985:325).

El presidente Pascual Ortíz Rubio manifestó ante el Congreso de la Unión su apoyo para la creación de infraestructura hidráulica. Mientras la Comisión Nacional de Irrigación se disponía a tales tareas, el gobernador Rodolfo Elías Calles solicitó al Secretario de Agricultura y Fomento, Fancisco S. Elías, la entrega de fondos para construír el canal de Tesia, obra necesaria para irrigar 1,300 hectáreas del Ejido Guayparín. El canal fue terminado en 1935. (Lorenzana, 2006:158) Transportes y vías de comunicación.

Miguel Ángel Siqueiros Murrieta, (Siqueiros, 2000) señala que hacia fines del siglo XIX, Sonora contaba con un sistema carretero que lo comunicaba con los estados vecinos y el extranjero, el cual abarcaba las principales ciudades, puertos y fronteras de la entidad. Había un camino central que hacía contacto con el resto del país por dos rutas: una al norte, de Álamos a Guaymas; del puerto a Hermosillo funcionaba la compañía de la familia Aguilar y Sucesores. Por el sur venía la carretera de Guadalajara - Tepic - Mazatlán - El Fuerte - Álamos.

Estos caminos, junto con los locales, eran recorridos por carretas, diligencias y recuas de mulas. Una de las diligencias de esa época era la que daba servicio de Álamos a Mazatlán, en tres corridas a la semana, saliendo los días martes, jueves y sábados de Álamos, pasando por El Fuerte, Sinaloa y Culiacán; otra compañía transitaba de Álamos a Guaymas, y de ese puerto a Hermosillo operaba la compañía de la familia Aguilar y Sucesores.

La costa oeste de México contaba con once líneas marítimas, nueve de las cuales atracaban con frecuencia en el puerto de Guaymas. De ellas, seis pertenecían a norteamericanos. Una línea británica, una mexicana y otra norteamericana hacían escalas frecuentes en San Francisco y Los Ángeles. Mientras que otras dos, una francesa y otra estadounidense, transportaban mercancía de 


\section{http://revistainvestigacionacademicasinfrontera.com}

San Francisco a Los Ángeles. Después de los mexicanos, los barcos de Estados Unidos eran los más comunes en Guaymas, ya que los puertos de San Francisco y Los Ángeles representaban el mercado más importante para los productores sonorenses.

Las principales rutas marítimas eran las que salían de Guaymas, considerado como puerto de altura. Las dos rutas internacionales más importantes eran la de Guaymas a la Paz, de la Paz a San Diego, y de ése puerto a San Francisco; la segunda de Guaymas a Centro y Sudamérica, para de ahí virar al estrecho de Magallanes y dirigirse a Europa. Estas rutas eran cubiertas por barcos y compañías extranjeras. Las ruta nacional recorría los principales puertos del Pacífico, la cubría la Línea Acelerada del Golfo de Cortés a través de la ruta Guaymas - Altata - La Paz - Mazatlán San Blas (Nayarit) - Manzanillo (Colima).

En 1881 se construyó el tramo ferroviario de Hermosillo a Guaymas y se estableció el servicio de carga y pasajeros entre este puerto y Nogales. En 1882, con destino a Estados Unidos, se construyeron otras vías como resultado de la inversión de la Sonoran Railway Company, una firma norteamericana con sede en Boston, que al colocar los primeros carriles, unió a Guaymas y Hermosillo con los mercados del otro lado de la frontera. Más tarde, se añadieron vías muertas que conectaron Cananea con Naco, lo que permitió exportar cobre. A partir de entonces, diariamente corrían ferrocarriles desde estaciones en Sonora hacia Arizona (Ruiz, 1999:105).

Este medio de transporte ofreció la posibilidad de incorporar los valles del Yaqui y Mayo a los mercados interno y externo, convirtiendo a Navojoa en centro ferroviario del sur del estado al construirse el ramal a Álamos y después el Ferrocarril del Río Mayo en 1922. A Navojoa llegaban de todo el valle los carretones jalados por bueyes con la producción de garbanzo, arroz, maíz y frijol para ser transportados, como aparece en lo informes de la compañía ferrocarrilera. (Gracida, 2004:5).

Cuando entró en operación el ferrocarril en el río Mayo el ramal de Navojoa a Álamos había prácticamente dejado de funcionar. Finalmente se levantó la vía en 1930. El efecto determinante de este medio de transporte se vería años después, cuando logra unir a todo el noroeste con el centro del país. 


\section{http://revistainvestigacionacademicasinfrontera.com}

ISSN: 2007-8870

En cuanto a otros medios de comunicación como el telégrafo y el teléfono, éstos empezaron a funcionar en la década de 1880. Las primeras líneas del telégrafo fueron inauguradas en mayo de 1880, de Ures a Hermosillo. Mazatlán fue comunicado con Álamos en abril de 1881, estableciéndose en dicha ciudad el centro de comunicaciones con el interior del país.

La infraestructura financiera.

Antes del surgimiento y consolidación de los intermediarios financieros en Sonora, las operaciones crediticias estuvieron en manos de los grandes comerciantes y prestamistas usureros, y en donde el papel de la iglesia como prestamista fue casi nulo. Esta actividad la llevaron a cabo los comerciantes de Álamos, Guaymas, Hermosillo y Nogales. Así como también los grandes mineros y terratenientes. Se observa que las formas de crédito prebancarias fueron importantes en el impulso de las actividades económicas durante la segunda mitad del siglo XIX en las diferentes regiones del norte del país. Estas actividades crediticias fueron desempeñadas por las casas mercantiles de la segunda mitad del siglo XIX a 1890, cuando aún no se definían las características del sistema bancario, es decir, antes de 1897. (Aguilar, 2001:27).

Ante las necesidades que iba generando la economía sonorense, se hizo evidente la necesidad de disponer de crédito y circulante. Por eso se hizo más apremiante el contar con un banco de emisión y crédito de capital local. En el estado, la presencia de los bancos se inició, como en la mayor parte de México, a través del establecimiento de corresponsalías y agencias de los primeros que se fundaron en la capital del país y en Chihuahua. Apareciendo, desde entonces, representantes de los diferentes intereses regionales localizados en Nogales y Magdalena, así como en Hermosillo y Guaymas.

El inicio del sistema bancario en Sonora fue un producto tardío del porfiriato. La Ley sobre Bancos e Instituciones de Crédito de 1897 dio lugar a que el año siguiente se fundara el Banco de Sonora en Hermosillo, y el Occidental de México, en Mazatlán. Durante más de veinte años fueron las dos únicas instituciones de crédito regionales. En 1911 se creó el Banco Hipotecario y Agrícola del Pacífico. En 1913 el Gobierno del Estado intervino las instituciones bancarias. Hasta 1916 la 


\section{http://revistainvestigacionacademicasinfrontera.com}

Agencia Comercial del Río Mayo, bajo la gerencia de Joaquín A. Morales, fungió como banquero durante ese difícil periodo.

El general Plutarco Elías Calles encabezó la organización de la Compañía Bancaria Mercantil y Agrícola de Sonora, S.A. en 1917, cuya participación como institución de crédito se manifestó hasta 1922. Los bancos participaron nuevamente en las actividades económicas en la entidad hasta 1918, año en que se abrieron algunas alternativas para la acumulación de capital financiero y el acceso al crédito con la formación de nuevas instituciones bancarias. Su competencia influyó para liberalizar las políticas del Banco de Sonora. No fue sino hasta 1922 cuando los productores agrícolas recibieron financiamiento, específicamente en los valles del Yaqui y Mayo para los cultivos de trigo, ajonjolí, arroz, garbanzo y algunas hortalizas (Grijalva, 2007)

El general Álvaro Obregón, junto con varios empresarios agrícolas del sur de Sonora y del norte de Sinaloa formaron el Banco Refaccionario de Occidente en 1926. Los accionistas, además de Obregón, eran: Ignacio P. Gaxiola, Diego Redo, Tomás Robinson Bours Jr., Crispín J. Palomares, Ignacio Gutiérrez Santacruz, Ignacio Ruiz, Blas Valenzuela, Salvador I. Campoy, José A. Morales y Gumaro Villalobos (Grijalva, 2007).

En 1933, Francisco L. Terminel y Waldo Morali solicitaron a la Secretaría de Hacienda y Crédito Público una concesión para fundar el Banco Agrícola Sonorense, la cual fue otorgada el 27 de abril de ese año. El domicilio de la sociedad se ubicó en Ciudad Obregón, pero podía establecer agencias o sucursales dentro y fuera del estado, además de representaciones en el extranjero. La idea era integrar varias asociaciones agrícolas para obtener financiamiento, creando la Confederación de Asociaciones Agrícolas del Estado de Sonora, representada por Fernando Aguilar y Jorge J. Parada, quienes fungen como presidente y secretario del Consejo de Administración (Grijalva, 2007: 8).

La banca en Sonora constituida durante el porfiriato sufrió un proceso de reestructuración después de la revolución. Por otra parte, la creación de nuevos bancos por Obregón y Calles favorecieron en gran medida el crédito a la actividad agrícola, principalmente en los valles del 


\section{http://revistainvestigacionacademicasinfrontera.com}

Yaqui y Mayo. Otros factores que alentaron el negocio de la agricultura fue el rescate de la Constructora Richardson por el Banco Nacional de Crédito Agrícola y la reestructuración bancaria que permitió financiar a los productores.

La formación del empresariado y la actividad agrícola en el Mayo.

Con la modernización de las haciendas se originó el despegue y consolidación de la agricultura comercial en la región. Casos como el de Ángel Almada, que empezó estableciendo una casa comercial a mediados de 1880 , y que para 1893 sería un próspero hombre de negocios, plenamente identificado con el porfirismo estatal. En la década de 1880 las únicas grandes unidades agrícolas en explotación eran las haciendas de Navojoa, Tres Hermanos y Santa Bárbara, que producían maíz, trigo, frijol y algunas legumbres para el mercado regional (Siqueiros, 2000:3).

A principios del siglo XX habían florecido en la región propiedades agrícolas, trigueras y garbanceras que dieron lugar a la constitución de importantes sociedades entre 1892 y 1902, tales como la Compañía Agrícola del Río Mayo, S.A. en San Pedro, con 6,400 hectáreas; Morales y García Peña, en la hacienda Juárez, la Sociedad Salido Hermanos, de José María, Epifanio e Ildefonso del mismo apellido, en la hacienda Rosales; la Sociedad José Tiburcio Otero e Hijos, de la familia Otero Esquer, en Jupateco, en el municipio de Huatabampo, y por último, la Sociedad Orrantia y Sarmiento, de Francisco Orrantia y Sarmiento, agricultor del valle del Fuerte, Sinaloa, y Pedro S. Quirós, de Navojoa (Siqueiros, 2000:28).

La Compañía Agrícola del Río Mayo, S.A., fue fundada en 1902, con un capital de $\$ 200,000.00$ pesos en los terrenos del pueblo de San Pedro, con 6,587 hectáreas, irrigadas por un canal de 8,652 metros de longitud, con un gasto de 10 mil litros por segundo, que en 1906 producía 1,500 hectolitros de garbanzo y dos mil de maíz, así como trigo y frijol. (Siqueiros, 2000:29).

Organizada por Ángel Almada, su fundador, que venía de una familia prominente de Álamos, con amplios intereses en la minería y el comercio. Los demás socios fundadores fueron: Jesús Guillermo Almada, Óscar Ocharan, Alberto Ramos, Manuel Larraguíbel, Joaquín S. Urrea y Felipe Ramos. Habiendo ingresado posteriormente Tomás Robinson Bours y hermanos, Ignacio E. Almada, Miguel C. Urrea, Reynaldo Ramos, M.R. de Velderráin, Banco de Sonora, S.A., 


\section{http://revistainvestigacionacademicasinfrontera.com}

ISSN: 2007-8870

Amparo E. viuda de Corral, José María Quiróz, Ignacio L. Almada, Alberto Almada, Redo y Cía., de El Dorado, Sinaloa, Jorge Le Brun, de Hermosillo, y el Lic. Guillermo Obregón, de la ciudad de México. El Consejo de Administración estaba integrado por: Ignacio E. Almada, Alberto Ramos, Óscar Ocharan y Joaquín S. Urrea.

El 3 de septiembre de 1909 aparecen registrados 71 socios en un Libro Mayor de esta compañía. Destacan entre ellos personajes de la política como Ramón Corral y Severiano Talamante. Figuran también bancos extranjeros como The Citizen National Bank, de los Ángeles, California, y Sonora Exchange \&Comission, Co.

Participaban inversionistas foráneos como Redo y Cía., de El Dorado, Sinaloa, Alberto Ramos y Valentín Zapatero del Distrito Federal. La mayoría de los socios pertenecían a las familias alamenses ya mencionadas. $^{2}$

En el archivo del Registro Público de la Propiedad de Álamos (RPPAS) se obtuvo información entre abril de 1905 y noviembre de 1913, en la que destacan las operaciones de compra - venta de terrenos y el otorgamiento de títulos de propiedad por parte del presidente de la república en los municipios de Navojoa, Etchojoa y Huatabampo. En esta fuente aparecen los apellidos de las familias alamenses como los Salido, Almada, Campoy, Palomares, entre otros. En el caso de Navojoa, además de varias operaciones de compra - venta de terrenos, se encuentran también compras de acciones de tomas de agua por la Compañía Agrícola del Río Mayo, S.A., la Sociedad Agrícola "Campoy Hermanos", la familia Salido, los Velderráin de la hacienda El Naranjo, en Huatabampo (Clark y Carrillo, 2006:31).

Se expidieron títulos de dominio sobre terrenos en el rancho Barebampo en Camoa a Óscar Ocharan, uno de los fundadores y socios más importantes de la citada compañía.Se entregó título de propiedad en favor de Pánfilo R. Santini sobre el predio de Chombacia, entre otras operaciones.

\footnotetext{
${ }^{2}$ Libro Mayor de la Compañía Agrícola del Río Mayo, S.A., Navojoa, 3 de septiembre de 1909. (Consultado en la Biblioteca privada del Dr. Ignacio Almada Bay).
} 


\section{http://revistainvestigacionacademicasinfrontera.com}

En 1905, la Sociedad “José María Salido y Cía.” compró a Dolores y María Ana Salido el terreno San José de Guadalupe, en Camoa ${ }^{3}$. Clotilde Gaxiola compró a Laura Talamante de Rosas en Capetamaya, Navojoa, 8,000 hectáreas de terreno ${ }^{4}$.

En Etchojoa se registraron varias operaciones de compra - venta de terrenos como la adquisición de 60 lotes en San Pedro por Leobardo Salido a Ángel Quiróz. ${ }^{5}$ Ramón Ross compró a Jesús Toledo y Vega treinta lotes de terreno y una acción de toma de agua en el canal Jupagogoli en Etchojoa y Huatabampo. ${ }^{6}$ Crispín Palomares compró terrenos en ese municipio a Adalberto de Córdova y a L.A. de Cárdenas. Otros agricultores que adquirieron terrenos en esos años fueron la familia Terrazas, Tomás P. Bay, José T. Obregón y Abelina Palafox.

En el municipio de Huatabampo uno de los pioneros en la exportación de garbanzo fue el general José Tiburcio Otero, que adquirió el predio Las Mil hectáreas. Trinidad B. Rosas, quien fuera apoderado legal de la Compañía Agrícola del Río Mayo, S.A., compró a José María Romero 300 hectáreas en Aquichopo. $^{7}$

El general Álvaro Obregón también realizó algunas operaciones, adquirió de Concepción viuda de Rojas el predio Bunijamino. ${ }^{8}$ Entre 1905 y 1913 se realizaron 28 contratos de compra venta de terrenos que suman un total de 8, 338 hectáreas, 138 lotes y medio, y 12 predios en el Mayo.

Al término del movimiento revolucionario, en los años de 1919 y 1920, se registraron algunas inscripciones relativas a contratos de compra - venta de terrenos y otorgamiento de títulos de propiedad. En Etchojoa, Tomás Robinson Bours Jr. y María Ramos de Robinson Bours adquirieron varios terrenos. Ángel Urbina compró la labor La Galera sobre la margen derecha del río. ${ }^{9}$ Se otorgaron títulos de propiedad en Etchojoa a Jesús Ruy Sánchez y Balvanera Zayas de

\footnotetext{
${ }^{3}$ Registro Público de la Propiedad de Álamos, L.I., vol. I, Escr. 97, 15-12-05.

${ }^{4}$ R.P.P.A., L.I., Vol.I, Escr. 498, 10-08-09.

${ }^{5}$ R.P.P.A., L.I., Vol. I, Escr. 95, 8-11-13.

${ }^{6}$ R.P.P.A. L.I., Vol. I, Escr. 102, 3-12-13

${ }^{7}$ R.P.P.A., L.I., Vol. I, Escr. 79, 2-11-05

${ }^{8}$ R.P.P.A., L.I.., Vol. I, Escr. 133, 4-06-06

9 R.P.P.A., L.I., Vol. IV, Escr. 19, 25-07-19
} 


\section{http://revistainvestigacionacademicasinfrontera.com}

ISSN: 2007-8870

Ruy Sánchez. ${ }^{10}$ En abril de 1920 se llevó a cabo la división y desmancomunación de la labor Las Parras, en los terrenos de la hacienda Jupateco, sobre la margen derecha del río, por Guadalupe Otero viuda de Otero y sus hijos José F., Rodrigo A. y Elodia Trinidad Otero de Terrazas. ${ }^{11}$

A partir de 1922 se advierte un incremento en la actividad de los agricultores, principalmente en el bajo río Mayo. Felizardo Velderráin obtuvo un préstamo por $\$ 2,000.00$ pesos de N.H. Ruby ofreciendo en garantía la siembra de garbanzo que tenía en la hacienda de San Pedro. ${ }^{12}$ En agosto, Manuel J. Güereña hipotecó a Tomás Robinson Bours Jr. 47 lotes y medio en la Colonia Santa Cruz de Huatabampo, y dos acciones del canal Constitucionalista en la cantidad de $\$ 17,648.26$ dólares. ${ }^{13}$

En 1923 se encuentran cinco operaciones en Navojoa y tres en Etchojoa. Se constituyó la Sociedad Mercantil y Agrícola "Palomares y Bórquez" en Navojoa con un capital social de $\$ 1,000.00$ pesos. ${ }^{14}$ En el mismo municipio se encuentran además tres contratos de compra de terrenos y una rescisión de otra operación igual. En Etchojoa hay tres operaciones diversas. En el Boletín Oficial del gobierno del Estado hay registradas tres solicitudes de concesiones para tomas de agua por parte de Joaquín Ruy Sánchez ${ }^{15}$, Leobardo Salido ${ }^{16}$ y Ubaldo S. Palomares. ${ }^{17}$

En 1924 se constituyeron tres sociedades agrícolas: la Sociedad Mercantil y Agrícola "Nicolás Contreras y Hermano"18, la Sociedad Agrícola "Sebastián Chacón y Cía.", en la que Sebastián Chacón aporta 300 hectáreas de terreno en la hacienda La Villa, Etchojoa. ${ }^{19}$ Y la sociedad "Almacenes de Navojoa, S.A.” formada por Tomás Robinson Bours Jr. y David J.

\footnotetext{
${ }^{10}$ R.P.P.A., L.I., Vol. IV, Escr. 132, 11-02-20

${ }^{11}$ R.P.P.A., L.I., Vol. IV, Escr. 147, 05-04-20

${ }_{12}$ Archivo Histórico del Gobierno del Estado de Sonora, Pedro Bórquez, Caja 127, 29-07-21, 47-48.

${ }^{13}$ AHGES, Pedro Bórquez, Caja 127, 25-08-22, 142, 294-295.

${ }^{14}$ AHGES, Cenobio Esquer, Caja 127, 14-07-23, 194, 248-250.

15 Boletín Oficial del Gobierno del Estado de Sonora, Tomo XIII, 25-07-23, No. 7.

${ }^{16}$ Boletín Oficial, Tomo XIII, 11-08-23, No. 12

${ }^{17}$ Boletín Oficial, Tomo XII, 7-05-23, No. 5.

${ }^{18}$ AHGES, Francisco L. Esquer, Caja 126, 5-01-24, 29, 70-72.

${ }^{19}$ AGHES, Antonio Maldonado y Osuna, Caja 126, 26-07-24, 78, 192-195.
} 


\section{http://revistainvestigacionacademicasinfrontera.com}

ISSN: 2007-8870

Palomares. ${ }^{20}$ Margarito Hayakawa realizó un contrato de arrendamiento por 225 hectáreas en el Sahuaral, Etchojoa con Luz T. viuda de Terminel. ${ }^{21}$

En 1925 sólo hay tres operaciones en Navojoa y una en Huatabampo. Se encuentra una escritura de cesión de terrenos de la Compañía Agrícola del Río Mayo, S.A. en favor del Ferrocarril del Río Mayo, para las estaciones de Bacobampo, Chucárit y San Pedro. ${ }^{22}$ En febrero se constituyó la Sociedad "Palomares y Retes", por Luis R. Palomares y Adolfo E. Retes. ${ }^{23}$ Se efectúa también una compra - venta otorgada por Dvid J. Dabdoub en favor de Ignacio Ruíz de 100 hectáreas en Huatabampo por la cantidad de $\$ 3,000.00$ pesos. $^{24}$

El 1 de septiembre de 1925 abrió sus puertas en Navojoa el Banco de México, S.A., y el 23 de marzo de 1926 se estableció el Banco Refaccionario de Occidente, S.A. Fue entonces cuando se realizaron los primeros préstamos de habilitación y avío por éste último, que en ése año concedió préstamos a la Sociedad “Araiza y Rivera", representada por Jesús C. Araiza, por la cantidad de \$2,500.00 dólares. Esta sociedad tenía terrenos en arrendamiento en el valle del Yaqui, en Cócorit y en la hacienda La Fortuna. ${ }^{25}$ Recibieron préstamos Carlos Obregón e Inocente Amparán, el primero por \$2,500.00 dólares, quien tenía en arrendamiento 250 hectáreas en la hacienda de Caurara, en Etchojoa. ${ }^{26}$ El préstamo a Amparán fue por \$7, 500.00 dólares, éste tenía en arrendamiento a la Compañía Richardson el Block No. 45 en el Yaqui, con 400 hectáreas de arroz y 50 de garbanzo. ${ }^{27}$

Trinidad B. Rosas vendió a Ignacio Ruíz varios lotes de terreno en el municipio de Huatabampo, 60 acciones de la Compañía de Regadío de Etchojoa y 10 acciones de la Compañía de Regadío de Tiriscohuasa por $\$ 15,000.00$ pesos. ${ }^{28}$ Los casos de la Sociedad “Araiza y Rivera"

\footnotetext{
${ }^{20}$ AHGES, Francisco L. Esquer, Caja 126, 31-12-24, 3, 70-72.

${ }^{21}$ AHGES, Antonio Maldonado y Osuna, Caja 126, 14-05-24, 57, 191.

${ }^{22}$ AHGES, Francico L. Esquer, Caja 126, 16-01-25, 9, 50-51.

${ }^{23}$ AHGES, Arturo Ulloa, Caja 126, 14-02-25, 28, 107-108.

${ }^{24}$ AHGES, Arturo Ulloa, Caja 126, 18-04-25, 33, 87-89.

${ }^{25}$ AHGES, Roberto H. Orellana, Caja 58, 23-04-25, 86, 53-60.

${ }^{26}$ AHGES, Roberto H. Orellana, Caja 58, 12-05-25, 106, 90 - 96.

${ }^{27}$ AHGES, Roberto H. Orellana, Caja 58, 20-10-26, 103, 67-74.

${ }^{28}$ AHGES, Roberto H. Orellana, Caja 58, 22-09-26, 83, 259-262.
} 


\section{http://revistainvestigacionacademicasinfrontera.com}

ISSN: 2007-8870

y de los agricultores Carlos Obregón e Inocente Amparán, reflejan un fenómeno que estuvo presente durante el periodo. Se trata de empresarios que fueron ampliando su radio de acción al adquirir propiedades e invertir en ambos valles y en diferentes giros. El principal ejemplo de este tipo de empresarios fue el general Álvaro Obregón, que tenía terrenos en los municipios del Mayo, la Sociedad “Obregón y Cía.” con oficina en Navojoa, y la hacienda Náinari en el Yaqui.

Desde 1926, Sonora había venido aumentando su participación nacional en la producción de trigo, ya que de un $11.4 \%$ pasó a aportar el 15.2\% en 1929. También en arroz la entidad se había convertido junto con Morelos en uno de los principales productores de este cereal gracias a la alta productividad del Yaqui, que desde 1925 tuvo que atender la demanda de los mercados norteamericano y europeo. (Ramírez y León, 1985: 30).

En el cultivo de maíz, el Mayo había incrementado su participación estatal, mientras que la aportación no comercial estaba repartida entre todas las unidades de producción en el estado. Otros cultivos como el garbanzo, el chícharo y el frijol ocupaban una amplia área cultivada; el garbanzo acaparó el $60 \%$ de la superficie cultivable del valle con el fin de atender la creciente demanda española, principalmente. ( Ramírez y León, 1985:30).

La agricultura empezó a sufrir a nivel nacional una caída en los precios de las exportaciones a partir de 1927 (azúcar, café, henequén, tomate y otros cultivos), pues se presentaron las luchas cristeras, las agrarias y la falta de crédito. Los efectos de esta situación se sintieron en el Mayo, además en el mismo año se registró una creciente que acabó con las cosechas. En los archivos aparece solamente la constitución de la sociedad civil "Obregón y Cía." registrada notarialmente el 15 de julio, ${ }^{29}$ pero venía operando desde septiembre de 1925. Álvaro Obregón y su apoderado legal Ignacio P. Gaxiola fueron inicialmente los únicos socios de esta firma que tenía su domicilio fiscal en Navojoa y un capital social de $\$ 2,300000.00$ pesos.

En 1928 se observa un relativo incremento de la actividad agrícola, mayormente en los municipios del bajo río Mayo, predominando los contratos de compra - venta de terrenos. Se llevó a cabo la compra del terreno Las Mil hectáreas en el municipio de Huatabampo por Ildefonso

\footnotetext{
${ }^{29}$ AHGES, Marcos Gómez, Caja 58, 15-08-27, 115.
} 


\section{http://revistainvestigacionacademicasinfrontera.com}

ISSN: 2007-8870

Salido a José T. Otero por la cantidad de $\$ 10,000.00$ pesos oro nacional. ${ }^{30}$ También Álvaro Obregón compró a Ricardo G. Hill 450 hectáreas, 37 áreas, tres quintos de área del terreno La Unión, y parte de la concesión del derecho de aprovechamiento de agua del río por la cantidad de $\$ 5,000.00$ pesos. $^{31}$ Alejo Bay vendió al general Benito Bernal la mitad del terreno El Yópori, en el municipio de Navojoa en \$3, 650.00 plata mexicana. ${ }^{32}$ Por último, aparece la eescritura de un préstamo que el Banco de Sonora concedió a Jesús María Quijada, por la cantidad de \$8,000.00 pesos. $^{33}$

A partir de este año empiezan a descender el número de operaciones. Sólo aparecen cuatro entre Navojoa y Huatabampo. Se encuentra la escritura de Sociedad Civil Particular otorgada por David Roy y Federico Dow, la Sociedad Agrícola y Ganadera "Dow y Roy" en la hacienda de Santa Rosa o Las Tablas, en el municipo de Navojoa. ${ }^{34}$ Otra sociedad es la formada por Humberto Ortíz, Bernardino, Esteban y Ángel Ibarrola, denominada "H. Ortíz y Compañía”. El primero de los socios era mexicano y los otros españoles. La sociedad con domicilio en Huatabampo se dedicaba a la agricultura y ganadería con un capital social de $\$ 10,000.00$ pesos. $^{35}$

En 1930 comenzó el derrumbe de la producción de cobre provocando la caída del comercio, del sistema financiero, la quiebra del Banco de Sonora, institución que constituía el soporte de la actividad financiera en el estado. Los efectos de la crisis minera tuvieron un alto costo para la entidad . En ese tiempo Sonora no contaba con una estructura independiente fincada en el mercado interno, sus principales actividades económicas dependían del capital y del mercado de Estados Unidos (Ramírez y León, 1985:69).

En este año se realizó una compra - venta en la que Telésforo Hurtado vendió a Arcadio Pacheco 53 hectáreas de terreno en El Bacame, municipio de Navojoa. ${ }^{36}$ También se constituyó

\footnotetext{
${ }^{30}$ AHGES, Fernando E. Moreno, Caja 57, 8-04-28, 82 - 90.

${ }^{31}$ AHGES, Fernando E. Moreno, Caja 57, 14-05-28,114, 178 - 182.

${ }^{32}$ AHGES, Fernando E. Moreno, Caja 57, 10-07-28, 151, 40-52.

${ }_{33}$ AHGES, Fernando E. Moreno, Caja 57, 12-11-28, 173, 21-23.

${ }^{34}$ AHGES, Jesús C. Araiza, Caja 58, 17-07-30, 83, 259, 262.

${ }^{35}$ AHGES, Jesús C. Araiza, Caja 58, 6-11-30, 100, 16-20.

${ }^{36}$ AHGES, Marcos Gómez, Caja 58, 17-07-30, 83, 259-262.
} 


\section{http://revistainvestigacionacademicasinfrontera.com}

ISSN: 2007-8870

como Sociedad Anónima la Compañía Exportadora de Sonora, S.A., formada por W.H. Jully y E.E. Oliver, con un capital social de $\$ 1,000.00$ pesos. ${ }^{37}$ En 1931 José T. Otero vendió a Benjamín y Aurelio Valenzuela 300 hectáreas en el predio rústico Las Mayas, en el municipio de Huatabampo por la cantidad de \$3,000.00 pesos plata mexicana. ${ }^{38}$ En junio de 1932 se llevó a cabo la protocolización del acta de la asamblea general extraordinaria de accionistas de la compañía “Canal Jupagogoli”, Sociedad Civil con capital social de \$25,000.00 pesos. ${ }^{39}$

En mayo de 1933 se llevó a cabo la protocolización de la primera asamblea de la Asociación de Productores de Garbanzo, Frijol y Cereales de la Región Agrícola del Mayo. ${ }^{40}$. Hay también cuatro operaciones de hipoteca, seis de compra-venta de terrenos, una escritura de cesión de terreno de la Compañía Agrícola del Río Mayo en favor del Ferroarril del Río Mayo para las estaciones de Bacobampo, Chucárit y San Pedro ${ }^{41}$, y una escritura de arrendamiento de la labor "Sahuaral" de 225 hectáreas, en los ejidos de Etchojoa, otorgada por Luz T. viuda de Terminel y Ricardo J. Terminel en favor de Margarito Hayakawa. ${ }^{42}$

En el municipio de Huatabampo se encuentran cinco hipotecas, tres contratos de compraventa de terrenos, una jurisdicción voluntaria e información ad - perpetuam promovidas por Arturo Rosas, dueño de 16 hectáreas de terreno. ${ }^{43}$

En síntesis, en el Archivo Histórico del Gobierno del Estado de Sonora (AHGES) se obtuvo información acerca de las operaciones mercantiles de los agricultores del Mayo entre 1921 y 1934. Y de 1935 a 1940 se consultaron archivos de la Dirección General de Notarías del Estado de Sonora (DGNES). En ambas fuentes se da cuenta, aunque de manera parcial, de las actividades realizadas por los propietarios agrícolas e inversionistas.

\footnotetext{
${ }^{37}$ AHGES, Marcos Gómez, Caja 58, 6-11-30, 100, 16-20.

${ }^{38}$ AHGES, Marcos Gómez, Caja 58, 6-11-30, 112, 56-58.

${ }^{39}$ AHGES, Delfino O. López, Caja 126, 30-06-32, 37, 110-123.

${ }^{40}$ AHGES, Jesús C. Araiza, Caja 60, 15-05-33, 512, 78-81.

${ }^{41}$ AHGES, Francisco L. Esquer, Caja 126, 16-01-25, 9, 50-51.

42 AHGES, Antonio Maldonado y Osuna, Caja 126, 14-05-24, 97, 191.

${ }^{43}$ AHGES, Delfino O. López, Caja 126, 23-06-32, 36, 105-108.
} 


\section{http://revistainvestigacionacademicasinfrontera.com}

ISSN: 2007-8870

En un recuento de las operaciones registradas en los protocolos notariales durante el periodo de estudio, se pueden observar cuatro etapas: en la primera, de 1921 a 1924 se advierte un proceso de ascenso en la actividad comercial con un total de 35 operaciones, en las que predomina la, compra - venta de terrenos, en segundo lugar las hipotecas, y luego la onstitución de sociedades.

En la segunda etapa, de 1925 a 1928, hay una disminución significativa en el número de operaciones, elevándose un poco entre 1925 y 1927. En 1928 se observa una leve recuperación. En la tercera etapa se aprecia una tendencia a la baja, con 15 operaciones, coincidente con la crisis de 1929.

Entre 1934 y 1935 no se encuentra información. La cuarta etapa se ubica dentro del periodo cardenista. Entre el 25 de febrero de 1936 y el 5 de diciembre de 1940 aparecen registradas 135 operaciones en el Archivo de Notarías del Gobierno del Estado de Sonora, 97 de esas operaciones corresponden a contratos de compra - venta de terrenos, le siguen en importancia las escrituras de constitución de sociedades anónimas, de sociedades en nombre colectivo, los contratos de hipoteca, contratos de arrendamiento de tierras, constitución de sociedades mercantiles de responsabilidad limitada, contratos de aparcería, préstamos con garantía prendaria y escrituras de disolución de sociedades, entre otras.

A lo largo del periodo, el número total de operaciones fue de 201, distribuidas entre los tres municipios: Navojoa 129; Etchojoa 33; y Huatabampo 39. Por tipo de operaciones se dividen en 117 contratos de compra - venta de terrenos, 16 escrituras de constitución de sociedades, 9 contratos de hipotecas, 5 compra - venta de acciones de tomas de agua, 3 préstamos de habilitación y avío, y el resto de operaciones diversas.

\section{Conclusiones.}

En Sonora, desde la independencia, los valles del sur fueron contemplados como el territorio idóneo para el asentamiento de colonos nacionales y extranjeros. La colonización fue impulsada como parte medular del proyecto liberal y estuvo estrechamente ligada al despliegue de acciones militares. Las campañas contra los indígenas muestran el carácter violento y depredador que 


\section{http://revistainvestigacionacademicasinfrontera.com}

ISSN: 2007-8870

caracterizó a dicho proceso, mismo que se acentúa durante la segunda mitad del siglo XIX y principios del XX. También jugaron un papel protagónico las compañías deslindadoras, que contribuyeron a consolidar no sólo la colonización, sino también la explotación agrícola de corte capitalista.

Con la finca de las haciendas y la apetura de canales de riego desde 1865, dio comienzo en el Mayo la agricultura comercial antes que en el Yaqui. De la conjugación de los factores básicos de tierra, agua y trabajo surgen las bases que cimentaron la formación de la región agrícola. Un catalizador importante de este proceso formativo de capitales fue el espíritu emprendedor de los primeros agricultores que incursionaron en la apertura de canales de riego y arriesgaron sus capitales al invertirlos en la agricultura.

A la construcción de obras de irrigación y la expansión de la frontera agrícola se suman la llegada del ferrocarril, la cercanía del mercado de los Estados Unidos, la formación de organizaciones gremiales como la Cámara Agrícola y Comercial del Río Mayo, S.A., y otras que se fundaron después, así como la creación de los primeros bancos.

Con los gobiernos posrevolucionarios, el Estado se constituye en un promotor del desarrollo económico y se da la combinación de la política y los negocios. Hay que considerar también el hecho, de que los miembros de la facción triunfante de la revolución eran originarios de Sonora, y particularmente del sur de la entidad. El general Álvaro Obregón dedicó sus esfuerzos a promover la agricultura y los negocios en la región, donde también se hizo de grandes propiedades, al igual que Calles, Benjamín Hill, Abelardo L. Rodríguez y otros.

En este escenario juega un papel importante el marco institucional creado por los gobiernos del Grupo Sonora, además de la organización gremial de los empresarios agrícolas y ganaderos, que al final les permitió sortear una serie de obstáculos, incluidas las reformas cardenistas, para fortalecer la vía capitalista en la agricultura local. 
Año 9, Núm. 23 (Julio- diciembre 2016)

\section{http://revistainvestigacionacademicasinfrontera.com}

ISSN: 2007-8870

Bibliografía.

Aguilar Aguilar, Gustavo. 2004. Banca y desarrollo regional en Sinaloa 1910 - 1994: México, Plaza y Valdez/UAS.

Aguilar Camín, Héctor. 1986.La frontera nómada y la revolución mexicana, México: Siglo XXI.

Clark Valenzuela E. y Arturo Carrillo Rojas. 2006. "La actividad agrícola empresarial en el valle del Mayo (1920 -1934)”, Culiacán: Revista Clío-UAS.

Collado, H. María del Carmen, 2000. "Las empresas y la politización de la economía entre 1876 y 1930: un recuento historiográfico”, en Secuencia, núm. 46, México, Instituto Mora.

Gracida Romo, Juan José. 2014. La historia del ferrocarril Sud-pacífico de México y del Río Mayo durante el Porfiriato y la Revolución Mexicana 1905 - 1932, Coleccción Fuentes de la historia, Hermosillo, Norwork, S.A. de C.V.

. 2010. "Historia económica de Sonora, 1900 - 1940”, en 100 años de población y desarrollo, T.I., Consejo Estatal de Población del Estado de Sonora, Hermosillo.

. 2009. "La economía de Sonora durante la segunda década del siglo

XX”, en Arturo Román Alarcón y Gustavo Aguilar Aguilar, (coords,) Historia económica de México: 9 casos regionales, Culiacán, Praxis/Universidad Autónoma de Sinaloa.

. 2004. Los ferrocarriles en el desarrollo agrícola del valle del Mayo,

(1902 -1931), Hermosillo: Centro INAH - Sonora.

. 1985. "Sonora Moderno, 1880 - 1929”, en Cynthia Radding (Coord.),

Historia General de Sonora, Hermosillo: Gobierno del Estado de Sonora.

Grijalva Díaz, Ana Isabel. 2007. La reestructuración de la banca y el crédito agrícola en Sonora durante la Revolución, 1918 - 1934, en

http:www.economia.unam.mx/cladhe/registro/ponencia/151 


\section{http://revistainvestigacionacademicasinfrontera.com}

Lorenzana Durán, Gustavo. 2006. “El avance de la frontera agrícola en el sur de Sonora (1890 1941)" en Carrillo Rojas, A. y Mario Cerutti, (coords.), Agricultura comercial, empresa y desarrollo regional en el Noroeste de México, Culiacán: UAS/UANL/CONACYT.

Mange, Joaquín A. 1933. "Historia del negocio del garbanzo", en Montaño E. Raúl y Octavio P. Gaxiola, Álbum del Mayo y del Yaqui. Directorio Comercial, 1933, Navojoa:

Montaño E. Raúl y Octavio P. Gaxiola. 1933.Álbum del Mayo y del Yaqui. Directorio Comercial, 1933, Navojoa.

Ulloa, N. Pedro. 1910.El Estado de Sonora y su situación económica, Hermosillo: Imprenta a cargo de A.B. Monteverde.

Radding Cynthia y Rosa María Ruiz. 1985. "La reconstrucción del modelo de progreso, 1919 1929”, en Historia General de Sonora, T.IV, Hermosillo: Gobierno del Estado de Sonora.

Ramírez, José C. y Ricardo León. 1985."El último auge”, en Cynthia Radding, Historia General de Sonora, T.V., Hermosillo: Gobierno del Estado de Sonora.

Santillán Domínguez. 1989. Everardo, La Cámara Agrícola y Comercial del Río Mayo, 1921 1932, Tesis de Licenciatura en Historia, Departamento de Antropología e Historia, Hermosillo: Universidad de Sonora.

Siqueiros Murrieta, Miguel Ángel. 2000. La reorganización de un espacio regional: Álamos Navojoa, 1890 -1910, Tesis de maestría en Hstoria Regional, Culiacán, UAS.

Fuentes de archivo.

Archivo Histórico del Gobierno del Estado de Sonora (AHGES)

Archivo de la Dirección General de Notarías del Estado de Sonora (ADGNES)

Boletín Oficial de Gobierno del Estado de Sonora

Registro Público de la Propiedad de Álamos, Sonora (RPPAS) 
Año 9, Núm. 23 (Julio- diciembre 2016)

Revista de Investigación

Académica sin Frontera ISSN: 2007-8870

http://revistainvestigacionacademicasinfrontera.com 